TITLE:

\title{
Nematomorph parasites drive energy flow through a riparian ecosystem
}

\section{$\operatorname{AUTHOR}(\mathrm{S})$ :}

Sato, Takuya; Watanabe, Katsutoshi; Kanaiwa, Minoru; Niizuma, Yasuaki; Harada, Yasushi; Lafferty, Kevin D.

\section{CITATION:}

Sato, Takuya ...[et al]. Nematomorph parasites drive energy flow through a riparian ecosystem. Ecology 2011, 92(1): 201-207

ISSUE DATE:

2011-01

URL:

http://hdl.handle.net/2433/139443

RIGHT:

(C) 2011 by the Ecological Society of America 


\title{
Nematomorph parasites drive energy flow through a riparian ecosystem
}

\author{
Takuya Sato, ${ }^{1,7}$ Katsutoshi Watanabe, ${ }^{2}$ Minoru Kanaina, ${ }^{3}$ Yasuaki Nitzuma, ${ }^{4}$ Yasushi Harada, ${ }^{5}$ \\ AND KeVIn D. LAFFERTY ${ }^{6}$

\begin{abstract}
${ }^{1}$ KYOUSEI Science Center for Life and Nature, Nara Women's University, Kita-Uoya Higashimachi, Nara 630-8506 Japan Sakyo-ku, Kyoto 606-8502 Japan

${ }^{3}$ Faculty of Bio-Industry, Tokyo University of Agriculture, 196 Yasaka, Abashiri-city, Hokkaido 099-2493 Japan Aichi Prefecture 468-9502 Japan

${ }^{5}$ Laboratory of Fish Population Dynamics, Faculty of Bioresources, Mie University, 1577 Kurimamachiya-cho, Tsu, Mie Prefecture 514-0102 Japan

${ }^{6}$ U.S. Geological Survey, Western Ecological Research Center, Marine Science Institute, University of California, Santa Barbara, California 93106 USA
\end{abstract} \\ ${ }^{2}$ Department of Zoology, Division of Biological Science, Graduate School of Science, Kyoto University, Kitashirakawa-Oiwakecho, \\ ${ }^{4}$ Laboratory of Environmental Zoology, Faculty of Agriculture, Meijo University, 1-501 Shiogamaguchi, Tenpaku-ku, Nagoya-city,
}

\begin{abstract}
Parasites are ubiquitous in natural systems and ecosystem-level effects should be proportional to the amount of biomass or energy flow altered by the parasites. Here we quantified the extent to which a manipulative parasite altered the flow of energy through a forest-stream ecosystem. In a Japanese headwater stream, camel crickets and grasshoppers (Orthoptera) were 20 times more likely to enter a stream if infected by a nematomorph parasite (Gordionus spp.), corroborating evidence that nematomorphs manipulate their hosts to seek water where the parasites emerge as free-living adults. Endangered Japanese trout (Salvelinus leucomaenis japonicus) readily ate these infected orthopterans, which due to their abundance, accounted for $60 \%$ of the annual energy intake of the trout population. Trout grew fastest in the fall, when nematomorphs were driving energy-rich orthopterans into the stream. When infected orthopterans were available, trout did not eat benthic invertebrates in proportion to their abundance, leading to the potential for cascading, indirect effects through the forest-stream ecosystem. These results provide the first quantitative evidence that a manipulative parasite can dramatically alter the flow of energy through and across ecosystems.

Key words: energy flow; indirect effect; manipulative parasite; Nematomorpha; riparian ecosystem, Japan.
\end{abstract}

\section{INTRODUCTION}

Manipulative parasites can potentially modify energy flow among organisms (Lafferty 1992, Lafferty and Morris 1996) and consequently affect the structure, dynamics, and functioning of food webs (Thompson et al. 2005, Lafferty et al. 2006, 2008, Lefèvre et al. 2009). Ecosystem-level effects should be proportional to the amount of biomass or energy flow altered by the parasite, emphasizing the need to quantify the effect of parasites on the biomass and energy flow within and among ecosystems (Kuris et al. 2008).

Some species of larval nematomorphs ("horsehair worms," Phylum Nematomorpha: Family Gordiidae) manipulate their arthropod hosts, such as crickets and grasshoppers, to seek water so the worm can emerge as an aquatic adult (Thomas et al. 2002, Biron et al. 2005, Hanelt et al. 2005, Ponton et al. 2006a, $b$, Libersat et al.

Manuscript received 26 August 2009; revised 27 April 2010; accepted 27 May 2010. Corresponding Editor: A. S. Flecker.

${ }^{7}$ Present address: Field Science Education and Research Center, Kyoto University, Kitashirakawa-Oiwakecho, Sakyoku, Kyoto 606-8502 Japan. E-mail: takuya@species.jp
2009). The movement of infected crickets at the water surface invariably attracts aquatic predators (Ponton et al. 2006a, $b$, Sato et al. 2008). Sometimes predators eat infected crickets before nematomorphs can emerge, but the parasitic worms often escape through the predators' gills, mouth, or anus. Unlike many parasites, nematomorphs do not parasitize the predators of their hosts (Ponton et al. 2006a, b).

In Japanese streams, endangered trout (otherwise known as Kirikuchi charr, Salvelinus leucomaenis japonicus) readily ingest camel crickets (Diestrammena elegantissima and D. asynamorus) and grasshoppers (Kinkiconocephalopsis koyasanesis and Psyrana japonica), hereafter referred to as orthopterans, that enter streams (Sato et al. 2008). These orthopterans are also final hosts for the nematomorph Gordionus spp. Because terrestrial insects are important components of trout diets in these oligotrophic streams (Wipfli 1997, Nakano et al. 1999, Kawaguchi and Nakano 2001), we speculated that nematomorphs could indirectly provide a key subsidy for trout by driving orthopterans to water (Sato et al. 2008). 
TABLE 1. Fish biomass and mean daily energy intake of Japanese trout (Salvelinus leucomaenis japonicus) in each season.

\begin{tabular}{|c|c|c|c|c|c|c|c|}
\hline \multirow[b]{2}{*}{ Season } & \multirow[b]{2}{*}{$\begin{array}{l}\text { Period } \\
\text { (d) }\end{array}$} & \multirow{2}{*}{$\begin{array}{c}\text { Fish } \\
\text { biomass } \\
(\mathrm{g} / 100 \\
\left.\mathrm{m}^{2}\right)\end{array}$} & \multirow{2}{*}{$\begin{array}{l}\text { Individual } \\
\text { fish mass } \\
\quad(\mathrm{g})\end{array}$} & \multicolumn{4}{|c|}{$\begin{array}{l}\text { Mean daily energy intake } \\
(\mathrm{kJ} / 100 \mathrm{mg} \text { dry mass of fish) }\end{array}$} \\
\hline & & & & Total & $\begin{array}{l}\text { Infected } \\
\text { orthopterans }\end{array}$ & $\begin{array}{l}\text { Terrestrial } \\
\text { invertebrates }\end{array}$ & $\begin{array}{c}\text { Aquatic } \\
\text { invertebrates }\end{array}$ \\
\hline $\begin{array}{l}\text { Early spring (1 March-- } \\
30 \text { April) }\end{array}$ & 60 & $153(107-199)$ & $10.1 \pm 5.5$ & $16(13-20)$ & $0.1(0-0.2)$ & $1(1-14)$ & $15(12-18)$ \\
\hline Late spring (1 May-30 June) & 60 & $144(101-187)$ & $9.5 \pm 3.9$ & $97(76-122)$ & 0 & $47(35-62)$ & $50(41-61)$ \\
\hline Summer (1 July-13 August) & 43 & $126(88-164)$ & $8.3 \pm 3.7$ & $64(42-87)$ & $6(2-10)$ & $43(31-55)$ & $15(10-22)$ \\
\hline $\begin{array}{l}\text { Nematomorph season } \\
\quad \text { (14 August-20 November) }\end{array}$ & 98 & $156(106-206)$ & $9.4 \pm 4.4$ & $222(152-306)$ & $185(132-248)$ & $24(15-34)$ & $14(4-25)$ \\
\hline $\begin{array}{l}\text { Winter (21 November- } \\
28 \text { February) }\end{array}$ & 99 & $69(52-86)$ & $6.7 \pm 2.4$ & $2(2-3)$ & 0 & $0.1(0-0.2)$ & $2(2-2)$ \\
\hline
\end{tabular}

Notes: Area-based energy intake of trout were calculated by multiplying mean energy intake of trout (per $100 \mathrm{mg}$ dry mass) by number of days and fish biomass under the assumption that mean energy intake of fish and fish biomass were constant within each of five seasons. Values for fish biomass and daily energy intake are given as mean and $95 \% \mathrm{CI}$. Values for individual fish mass are given as mean $\pm \mathrm{SD}$. The study was conducted in a headwater stream in the Totsu River system, Kii Peninsula, Honshu, Japan.

Here, we quantified the extent to which this parasite's unusual life history strategy altered the flow of energy from forest to stream. Nematomorphs were so common that trout received the bulk of their annual energy needs in the form of infected orthopterans. In turn, trout satiation may have reduced trout predation on benthic invertebrates.

\section{Methods \\ Study site}

The study site was a headwater stream in the Totsu River system, Kii Peninsula, Honshu, Japan $\left(34^{\circ} 5^{\prime} \mathrm{N}\right.$, $135^{\circ} 33^{\prime} \mathrm{E}$ ), and had a drainage area of $1.14 \mathrm{~km}^{2}$. The study reach was $0.7 \mathrm{~km}$ in length, $8.4 \%$ in gradient, $2-5$ $\mathrm{m}$ in width, and was composed of pools $\left(572 \mathrm{~m}^{2}\right)$ and riffles $\left(422 \mathrm{~m}^{2}\right)$. Discharge at baseline flow was $3.7 \pm 0.7$ $\mathrm{m}^{3} / \mathrm{s}$. Bottom substrates were mainly pebble (17-64 mm) and cobble $(65-256 \mathrm{~mm})$. Monthly mean water temperatures varied from $0^{\circ} \mathrm{C}$ in February to $18.5^{\circ} \mathrm{C}$ in August. Planted coniferous trees (Cryptomeria japonica and Chamaecyparis obtusa) and small numbers of secondary-growth deciduous trees (e.g., Fraxinus spaethiana, Lindera triloba, and some species of the genus Acer) dominated the surrounding riparian forest (canopy cover: $70-100 \%)$. Endangered trout (Salmonidae: Salvelinus leucomaenis japonicus) and small numbers of minnows (Cyprinidae: Phoxinus oxycephalus jouyi) inhabited the study stream. Camel crickets (Rhaphidophoridae: Diestrammena elegantissima, D. asynamorus) and grasshoppers (Tettigoniidae: Kinkiconocephalopsis koyasanesis and Psyrana japonica) infected with adult horsehair worms (Gordionus spp.) were common in the riparian forest (Sato et al. 2008).

\section{Predation by trout on terrestrial hosts and other prey}

To determine diet, we captured trout $(>100 \mathrm{~mm}$ in fork length, $n>20$ ) using battery-powered backpack electrofishing units operating at $300-\mathrm{V}$ pulsed DC. Diet collections were made once per month (April 2007March 2008) except during the fall, when we sampled at 10 -d intervals. After capture, we immediately anesthe- tized fish using 2-phenoxyethanol (200-300 ppm), measured fork length (FL) to the nearest $1 \mathrm{~mm}$ and mass to the nearest $0.1 \mathrm{~g}$, and quickly pumped the stomach contents (Giles 1980) before releasing the fish on-site. Stomach contents were separated into aquatic adult insects, benthic prey, terrestrial host species, and terrestrial non-host taxa.

\section{Energy intake and growth of trout}

We estimated trout growth and population size using sequential captures of tagged fish (Ricker 1975). On each date, we collected individual fish $(>100 \mathrm{~mm}$ in FL, $n=3-10)$ every $4 \mathrm{~h}(04: 00,08: 00,12: 00,16: 00,20: 00$, and 24:00) over a 24-h period. Captured fish were measured and marked individually for growth calculation, and their pumped stomach contents were preserved in $70 \%$ ethanol. To minimize effects of multiple captures by electrofishing on trout behavior and feeding rates, we did not sample the same $20-\mathrm{m}$ reach more than once during a sampling date. Trout stomach contents were identified to species for terrestrial orthopterans and to order for other terrestrial invertebrates and aquatic invertebrates. Individual prey were measured to the nearest $0.01 \mathrm{~mm}$ using calipers, dried at $60^{\circ} \mathrm{C}$ for $24 \mathrm{~h}$, and weighed to the nearest $0.01 \mathrm{mg}$. From these data, we estimated individual- and population-based energy intake by trout. Daily prey consumption of terrestrial hosts and non-hosts and aquatic invertebrates by trout (as prey dry mass per $100 \mathrm{mg}$ dry mass of fish) were estimated separately using the food consumption model of Elliott and Persson (1978), which incorporated a temperature-dependent gastric evacuation rate into the calculation. Mass of daily prey consumption was converted into caloric values based on energy values of each invertebrate category (Appendix A: Table A1). Consumption and caloric data were aggregated to estimate the annual area-based calories consumed by the trout population, assuming mean daily energy intake per fish and fish biomass (range $=69 \pm 17 \mathrm{~g}$ to $156 \pm 50$ $\mathrm{g}$ dry mass per $100 \mathrm{~m}^{2}$ [mean $\left.\pm \mathrm{SE}\right]$ ) were constant within each of five seasons using data collected from two 
dates within each season (Table 1). Appendix A provides details of the energy calculations.

Individual trout growth rate $(G)$ per season was calculated using the standard formula (Wootton 1998): $G=\left(L_{2}-L_{1}\right) /\left(t_{2}-t_{1}\right)$, where $L_{1}$ and $L_{2}$ are lengths at times $t_{1}$ and $t_{2}$. The condition factor $(K)$ was also calculated using the formula $K=$ mass $/(\text { length })^{3}$ (Wootton 1998).

\section{Seasonal dynamics of prey abundance}

Terrestrial invertebrate inputs to the stream were determined using six dark-green pan traps $(0.76 \times 0.47$ $\mathrm{m}$ area, $20 \mathrm{~cm}$ deep) filled with water (depth $>5 \mathrm{~cm}$ ) and $\sim 5 \mathrm{~mL}$ of surfactant. Pan traps (hereafter referred to as stream traps) were randomly distributed throughout the study reach, with at least $20 \mathrm{~m}$ between individual traps, for 5-7 days in every month of the study. Invertebrates captured in the pans were sieved through an aquarium net (225- $\mu \mathrm{m}$ mesh) every two or three days during trap deployment. Every month (except for October 2007 and February 2008), the density of benthic stream invertebrates was estimated using a Surber sampler $(25 \times 25 \mathrm{~cm}$ in quadrat area, $1 \mathrm{~m}$ net length, 225- $\mathrm{mm}$ mesh) in six pools and six riffles, with at least $20-\mathrm{m}$ intervals between samples. In pools with low current, collectors created turbulence with their hands to drive dislodged invertebrates into the Surber net. Invertebrate samples were preserved in $70 \%$ ethanol and processed as described in Energy intake and growth of trout, except that orthopterans were dissected before drying to determine the presence/absence of nematomorph infections.

To assess the terrestrial abundance of orthopterans throughout the year, we used six traps (upland traps) made from plastic boxes (length $\times$ width $\times$ height: $100 \times$ $230 \times 90 \mathrm{~mm})$ with a one-way entrance $(23 \mathrm{~mm}$ in bore diameter) and baited with a $10-\mathrm{mL}$ solution of a 1:1 ratio of beer (Kirin Tanrei, Kirin Brewery, Kobe, Hyogo Prefecture, Japan) and soft drink (Calpis, Osaka, Japan). Upland traps were randomly distributed in the forest (5$15 \mathrm{~m}$ from the stream) for one or two days at monthly intervals, with at least $20 \mathrm{~m}$ between individual traps. Captured crickets were preserved in $70 \%$ ethanol for laboratory determinations of nematomorph infections.

We estimated the relative rate $(\alpha)$ that orthopterans enter streams if infected by nematomorphs following Lafferty (1992): $\alpha=\left(h_{\mathrm{i}} / H_{\mathrm{i}}\right) /\left(h_{\mathrm{u}} / H_{\mathrm{u}}\right)$, where $h_{\mathrm{i}}$ and $h_{\mathrm{u}}$ are the proportions of infected and uninfected orthopterans in stream traps and $H_{\mathrm{i}}$ and $H_{\mathrm{u}}$ are the proportions of infected and uninfected orthopterans in upland traps. Under the conservative assumption that trout did not selectively prey on infected hosts encountered in the stream, " $\alpha$ " can be regarded as the increased predation rate of orthopterans by trout if the orthopterans are infected by nematomorphs.

\section{Data analysis}

We used generalized linear models (GLM) and a generalized linear mixed model (GLMM) (Faraway
2006) to test the effects of measured variables on seasonal changes in prey abundance and trout growth and the ingestion of benthic invertebrates by trout. We included all interaction terms of two orders in initial models and used Akaike information criterion (AIC) to select the optimal model for each analysis. We used GLM to test the effects of month and location on the abundance of each prey type (orthopterans, other terrestrial invertebrates, adult aquatic insects), as well as the effects of these terms and habitat (pool vs. riffle) on benthic invertebrates. A GLMM was used to test whether trout growth was associated with initial body length, condition factor, and season, with trout individuals treated as a random effect. To explore the effects of the nematomorph season (fall) on the benthic community, we used GLM to test whether the mass of benthic invertebrates ingested by a trout was associated with trout size, water temperature, and benthic prey abundance outside and during the fall when nematomorph parasites were maturing in their orthopteran hosts (hereafter called the nematomorph season, from midAugust to mid-November). We also used GLM to explore the effects of trout size, mass of the terrestrial host and non-host species ingested by trout, time of day, and day and season on benthic invertebrate ingestion by trout. The assumption of normality of the residuals was assessed using Q-Q plots, and some variables were log transformed to meet the assumption.

\section{RESUlTS}

\section{Host manipulation, food abundance, and energy intake of trout}

We observed large seasonal changes in insect prey abundance and energy inputs. Adults of aquatic insects fell into the stream primarily in the spring, whereas terrestrial insects entered into the stream most frequently in the summer. Infected orthopteran inputs were greatest in the summer and fall (Fig. 1A) when benthic invertebrates were least abundant (Fig. 1B). Prevalence of nematomorph infection in camel crickets was much higher in stream traps (11 out of 12 crickets) than in upland traps (64 out of 179; Fisher's exact test, $P<$ $0.001)$.

During nematomorph season, most trout $(65 \% \pm$ $13 \%, 45-86 \%, n=10)$ had orthopterans in their stomachs (see Appendix B: Fig. B1). Under the conservative assumption that trout did not selectively prey on infected hosts encountered in the stream, orthopterans were 20 times more likely to be eaten by trout if infected by a nematomorph.

An orthopteran represented a very high energy value for trout $(3.1 \pm 1.7 \mathrm{~kJ}$ [mean $\pm \mathrm{SD}$ ] for each cricket and $0.4 \pm 0.1 \mathrm{~kJ}$ for each grasshopper). In comparison, uninfected terrestrial invertebrates $(0.1 \pm 0.2$ to $0.8 \pm$ $0.3 \mathrm{~kJ}$ per individual), adult aquatic insects $(0.1 \pm 0.1$ to $0.8 \pm 1.0 \mathrm{~kJ}$ per individual), and benthic invertebrates $(0.04 \pm 0.02$ to $0.2 \pm 0.3 \mathrm{~kJ}$ per individual $)$ had much lower energy contents (Appendix A: Table A1). As a diet 


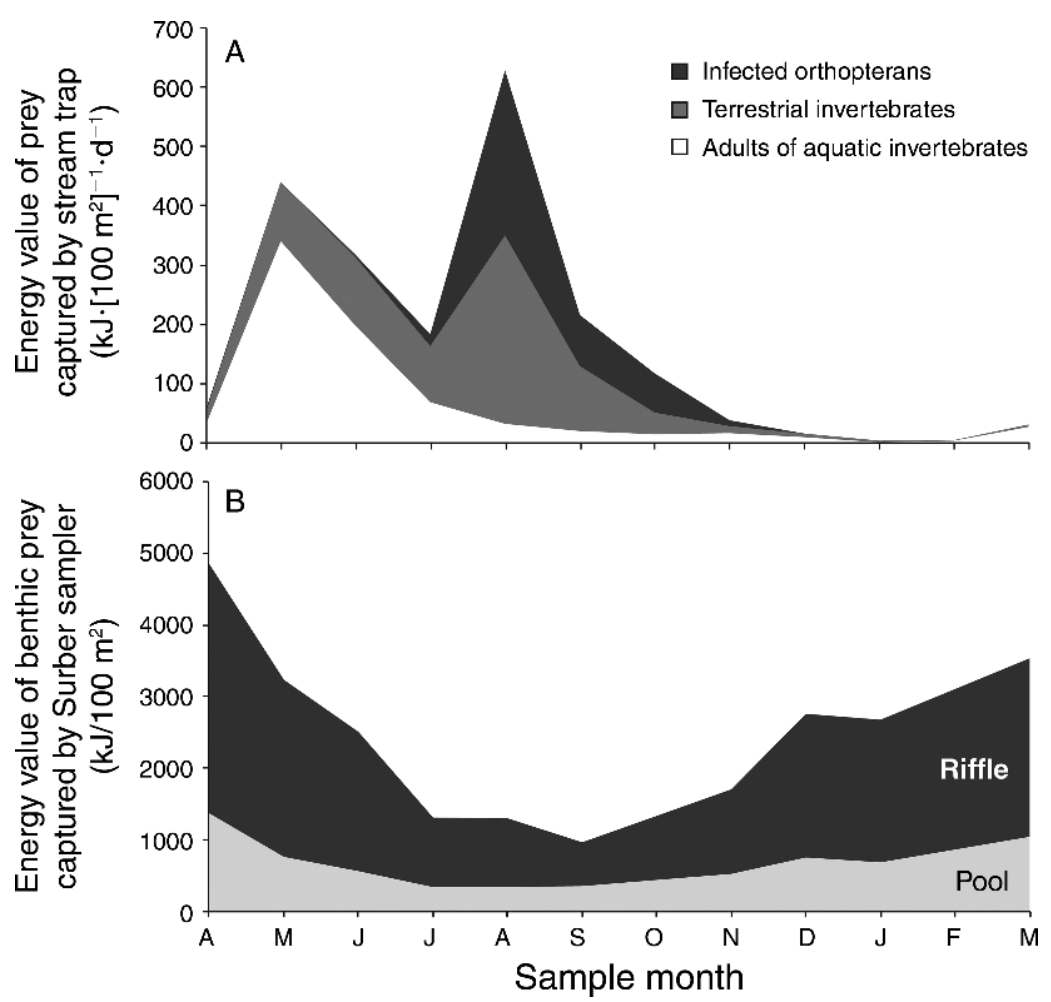

FIG. 1. Monthly mean abundance of Japanese trout (Salvelinus leucomaenis japonicus) prey expressed in terms of energy: (A) terrestrial and adult aquatic prey input per $100 \mathrm{~m}^{2}$ per day and (B) benthic prey per $100 \mathrm{~m}^{2}$. October and February values for benthic prey were interpolated from adjacent months. There were significant seasonal changes in the abundances of prey categories, i.e., infected orthopterans $\left(F_{11,60}=5.61, P<0.0001\right)$, terrestrial invertebrates $\left(F_{11,60}=20.69, P<0.0001\right)$, adults of aquatic invertebrates $\left(F_{11,60}=24.33, P<0.0001\right)$, and benthic prey $\left(F_{9,109}=13.84, P<0.0001\right)$, as well as differences between riffles and pools in benthic invertebrate abundance $\left(F_{1,118}=109.12, P<0.0001\right)$. The study was conducted in a headwater stream in the Totsu River system, Kii Peninsula, Honshu, Japan.

category, infected orthopterans were the dominant source of energy for trout $(\sim 80 \%)$ relative to other food types during the nematomorph season (Fig. 2). Nematomorphs also dramatically increased the absolute amount of energy obtained by trout: the daily energy intake per trout was 2.3-102.1 (30 \pm 48) times higher during nematomorph season compared to the other seasons $(95 \%$ CIs for the nematomorph season did not overlap those for other seasons; Table 1). Integration of trout energy acquisition throughout the year indicated that parasitized orthopterans comprised $\sim 60 \%$ of the annual caloric intake of the trout population (Fig. 3, Table 1).

\section{Indirect effects of parasitism on the stream community}

Trout grew fastest during the nematomorph season, a time when other types of prey were relatively uncommon (Fig. 1). Specifically, GLMM analysis indicated that growth (controlling for body size) was significantly higher during the nematomorph season compared to other time periods $\left(F_{4,48}=13.66, P<0.0001\right.$; see Appendix C: Table C1).

The trout population consumed benthic invertebrates in proportion to their abundance outside the nemato- morph season $\left(F_{1,148}=130.07, P<0.0001\right.$; Appendix C: Table C2.1) but not during the nematomorph season $\left(F_{1,68}=1.99, P=0.16\right.$; Appendix C: Table C2.2). Moreover, during the nematomorph season, trout consumption of benthic invertebrates declined compared with the other seasons and reached low levels as the consumption of infected orthopterans increased (season, $F_{4,215}=35.91, P<0.0001$; orthopterans ingested, $F_{1,119}=399.56, P<0.0001$; Appendix $\mathrm{C}$ : Table C3).

\section{DisCUSSION}

While many parasites manipulate the behavior of their hosts (Moore 2002), it is not known whether this has indirect energy implications for non-hosts such as trout in this system. The striking quantity of infected orthopterans eaten by the trout population is the first quantitative evidence that manipulative parasites can substantially alter the flow of energy within and among ecosystems (Fig. 3). Thus, the persistence of endangered trout, otherwise limited by scarce resources in oligotrophic streams, might even depend on the nematomorph.

Nematomorphs could also have major indirect effects on the benthic community. In oligotrophic streams, 


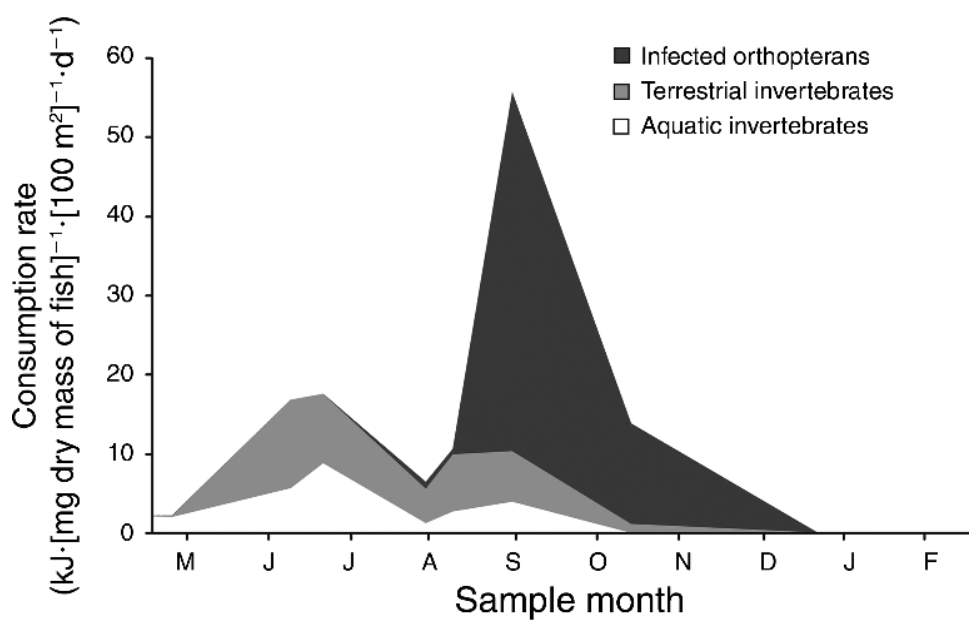

FIG. 2. Energy values of different prey categories consumed by Japanese trout (Salvelinus japonicus) over the study period. Infected camel crickets (Orthoptera) dominated trout diets in the fall and made up the majority of the annual energy intake.

terrestrial invertebrates that enter the water constitute an important food subsidy for salmonids (Wipfli 1997, Kawaguchi and Nakano 2001), and predator satiation can release benthic invertebrates from predation $(\mathrm{Na}-$ kano et al. 1999). In this Japanese stream, the greater availability of infected orthopterans to trout appears to have reduced the per trout predation pressure on benthic invertebrates. This is consistent with mathematical models that find positive indirect effects can occur among prey that share a predator if the predator is easily satiated and does not have a strong numerical response (Abrams and Matsuda 1996). Although we cannot determine rates of trout consumption of benthic invertebrates if the nematomorph was absent, the parasite-induced food subsidy to the trout population during the nematomorph season (approximately three months) was equivalent to 407971 benthic invertebrates (more than three times the estimated annual consump-

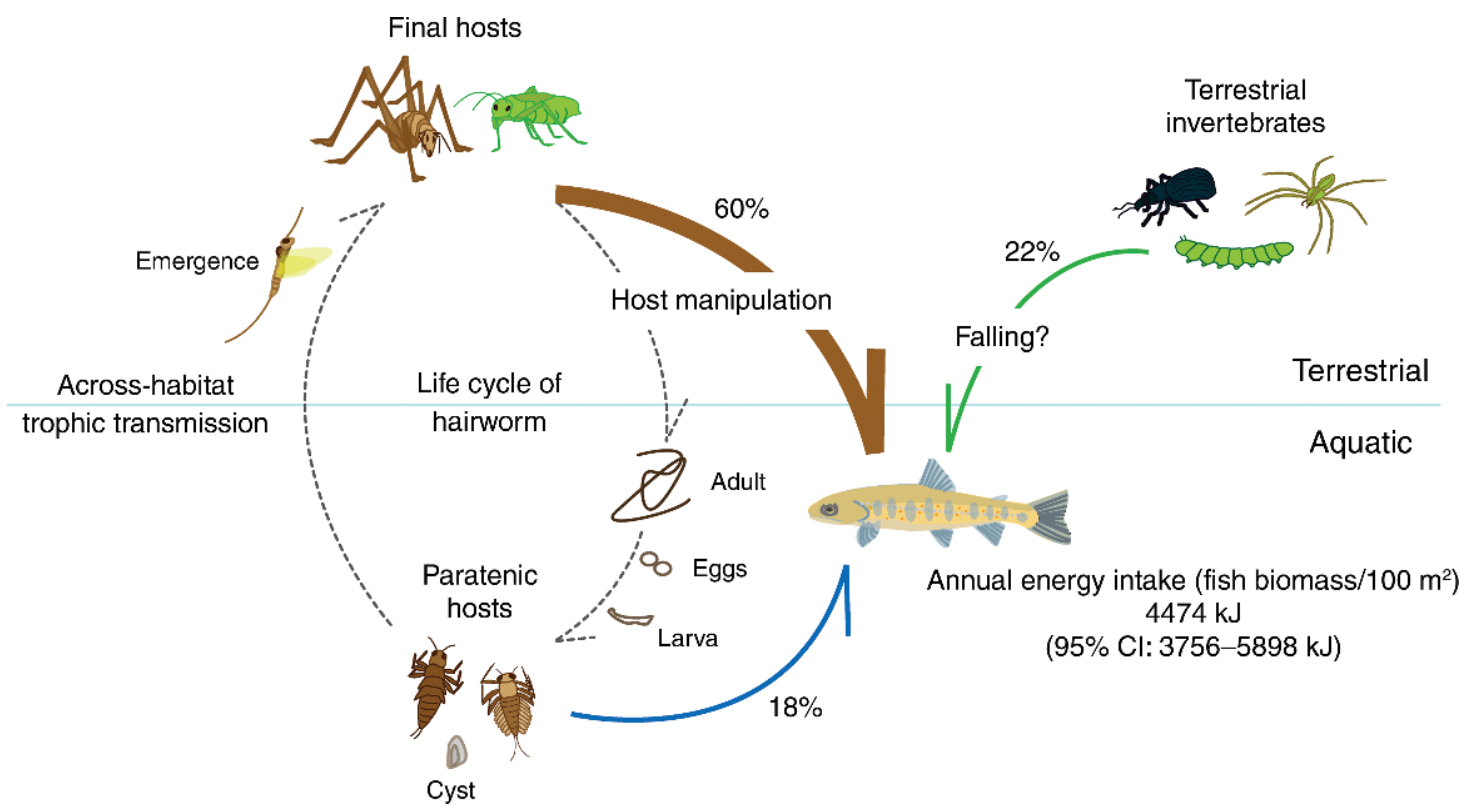

FIG. 3. Depiction of the life cycle of the hairworm Gordionus chinensis and the nematomorph-induced energy flow from forest to stream. Final hosts for the nematomorphs included at least four species of orthopterans, Tachycines elegantissima, T. asynamorus, Kinkiconocephalopsis koyasanesis, and Psyrana japonica, but the two species of Tachycines contributed $95 \%$ of trout energy intake of orthopterans. Endangered Japanese trout (Salvelinus leucomaenis japonicus) are predators on G. chinensis hosts but do not act as hosts themselves. Percentages of the energy obtained annually by the trout population from each prey category (infected orthopterans, terrestrial invertebrates, and aquatic invertebrates) are shown. 
tion of 125431 benthic invertebrates). Although each trout might consume fewer benthic invertebrates when orthopterans are available, if the subsidy leads to greater trout density in the long term (i.e., numerical response), the net indirect effect of the subsidy on benthic invertebrates could be negative (Sabo and Power 2002). Alteration of the benthic community could have further effects on the ecosystem functioning we have not documented, including algal production and leaf litter processes (Nakano et al. 1999, Greig and McIntosh 2006).

Predation on aquatic insects can indirectly alter ecosystem processes in adjacent terrestrial systems (Knight et al. 2005). For instance, by modifying trout predation on benthic invertebrates, the parasite-induced subsidy might indirectly change the number of adult insects that emerge from the stream (Baxter et al. 2004, 2005, Power et al. 2004). Many terrestrial consumers (e.g., birds and lizards) feed on these insects (Nakano and Murakami 2001, Murakami and Nakano 2002, Sabo and Power 2002), so parasites may indirectly change food subsidies from the stream to the forest.

In summary, nematomorphs manipulated infected camel cricket and grasshopper hosts to seek water, leading to a subsidy for an endangered trout population (Fig. 3). The combination of the intense manipulation of the orthopteran hosts by the nematomorph parasite and the high density of infected orthopterans in the surrounding terrestrial habitat led to a substantial indirect effect of parasites on the diet of trout. This parasite-altered flow of energy from terrestrial to aquatic habitats increased trout growth and presumably secondary production. Terrestrial-aquatic feedbacks are important to ecosystem dynamics (Baxter et al. 2005). Thus, we speculate that trout consumption of orthopterans during the nematomorph season could affect benthic invertebrates through the modification of trout predation pressure, indirectly affecting terrestrial predators of insects that emerge from the stream and enter the forest. Nematomorphs occur throughout the world (Poinar 2008) and commonly manipulate host behavior. Although the adult worms are sometimes only rarely seen, surveys for larvae indicate they can be among the most common parasites in aquatic systems (Hanelt et al. 2001), suggesting they might have a widespread role in moving terrestrial resources into aquatic habitats.

\section{ACKNOWLEDGMENTS}

We thank K. Wada, Y. Yusa, Y. Taniguchi, K. D. Fausch, T. Lefèvre, J. Shaw, and S. Cooper for comments on our draft paper; A. Ichikawa and A. Schmidt-Rhaesa for their species identification of orthopterans and nematomorphs, respectively; N. Oji, N. Suzuki, H. Maruyama, and H. Yamada for their assistance in the field survey; and the Nara Prefecture Board of Education, local governments, and the fisheries cooperative near the study area for approving the field survey. This research was supported in part by Sasagawa Scientific Research Grant (number 19-515) in 2007. Any use of trade, product, or firm names in this publication is for descriptive purposes only and does not imply endorsement by the U.S. government.

\section{Literature Cited}

Abrams, P. A., and H. Matsuda. 1996. Positive indirect effects between prey species that share predators. Ecology 77:610616.

Baxter, C. V., K. D. Fausch, M. Murakami, and P. L. Chapman. 2004. Fish invasion restructures stream and forest food webs by interrupting reciprocal prey subsidies. Ecology 85:2656-2663.

Baxter, C. V., K. D. Fausch, and W. C. Saunders. 2005. Tangled webs: reciprocal flows of invertebrate prey link streams and riparian zones. Freshwater Biology 50:201-220.

Biron, D. G., L. Marché, F. Ponton, H. D. Loxdale, N. Galéotti, C. Joly, and F. Thomas. 2005. Behavioural manipulation in a grasshopper harbouring hairworm: a proteomics approach. Proceedings of the Royal Society B 272:2117-2126.

Elliott, J. M., and L. Persson. 1978. The estimation of daily rates of food consumption for fish. Journal of Animal Ecology 47:977-991.

Faraway, J. J. 2006. Extending the linear model with R: generalized linear, mixed effects and nonparametric regression models. Chapman and Hall/CRC, Boca Raton, Florida, USA.

Giles, N. 1980. A stomach sampler for use on live fish. Journal of Fish Biology 16:253-261.

Greig, H. S., and A. R. McIntosh. 2006. Indirect effects of predatory trout on organic matter processing in detritusbased stream food webs. Oikos 112:31-40.

Hanelt, B., L. E. Grother, and J. Janovy. 2001. Physid snails as sentinels of freshwater nematomorphs. Journal of Parasitology 87:1049-1053.

Hanelt, B., F. Thomas, and A. Schmidt-Rhaesa. 2005. Biology of the phylum nematomorpha. Advances in Parasitology 59: 243-305.

Kawaguchi, Y., and S. Nakano. 2001. Contribution of terrestrial invertebrates to the annual resource budget for salmonids in forest and grassland reaches of a headwater stream. Freshwater Biology 46:303-316.

Knight, T. M., M. W. McCoy, J. M. Chase, K. A. McCoy, and R. D. Holt. 2005. Trophic cascades across ecosystems. Nature 437:880-883.

Kuris, A. M., et al. 2008. Ecosystem energetic implications of parasite and free-living biomass in three estuaries. Nature 454:515-518.

Lafferty, K. D. 1992. Foraging on prey that are modified by parasites. American Naturalist 140:854-867.

Lafferty, K. D., A. P. Dobson, and A. M. Kuris. 2006. Parasites dominate food web links. Proceedings of the National Academy of Sciences USA 103:11211-11216.

Lafferty, K. D., and A. K. Morris. 1996. Altered behavior of parasitized killifish increases susceptibility to predation by bird final hosts. Ecology 77:1390-1397.

Lafferty, K. D., et al. 2008. Parasites in food webs: the ultimate missing links. Ecology Letters 11:533-546.

Lefèvre, T., C. Lebarbenchon, M. Gauthier-Clerc, D. Missé, R. Poulin, and F. Thomas. 2009. The ecological significance of manipulative parasites. Trends in Ecology and Evolution 24: 41-48.

Libersat, F., A. Delago, and R. Gal. 2009. Manipulation of host behavior by parasitic insects and insect parasites. Annual Review of Entomology 54:189-207.

Moore, J. 2002. Parasites and the behavior of animals. Oxford University Press, Oxford, UK.

Murakami, M., and S. Nakano. 2002. Indirect effect of aquatic insect emergence on a terrestrial insect population through bird predation. Ecology Letters 5:333-337. 
Nakano, S., H. Miyasaka, and N. Kuhara. 1999. Terrestrialaquatic linkages: Riparian arthropod inputs alter trophic cascades in a stream food web. Ecology 80:2435-2441.

Nakano, S., and M. Murakami. 2001. Reciprocal subsidies: dynamic interdependence between terrestrial and aquatic food webs. Proceedings of the National Academy of Sciences USA 98:166-170.

Poinar, G. O., Jr. 2008. Global diversity of hairworms (Nematomorpha: Gordiaceae) in freshwater. Hydrobiologia 595:79-83.

Ponton, F., C. Lebarbenchon, T. Lefèvre, D. G. Biron, D. Duneau, D. P. Hughes, and F. Thomas. 2006a. Parasitology: Parasite survives predation on its host. Nature 440:756.

Ponton, F., C. Lebarbenchon, T. Lefèvre, F. Thomas, D. Duneau, L. Marché, L. Renault, D. P. Hughes, and D. G. Biron. 2006b. Hairworm anti-predator strategy: a study of causes and consequences. Parasitology 133:631-638.

Power, M. E., W. E. Rainey, M. S. Parker, J. L. Sabo, A. Smyth, S. Khandwala, J. C. Finlay, F. C. McNeely, K. Marsee, and C. Anderson. 2004. River-to-watershed subsidies in an old-growth conifer forest. Pages $217-240$ in G. A. Polis, M. E. Power, and G. R. Huxel, editors. Food webs at landscape level. University of Chicago Press, Chicago, Illinois, USA.
Ricker, W. E. 1975. Computation and interpretation of biological statistics of fish populations. Bulletin 191. Fisheries Research Board of Canada, Ottawa, Ontario, Canada.

Sabo, J. L., and M. E. Power. 2002. Numerical response of lizards to aquatic insects and short-term consequences for terrestrial prey. Ecology 83:3023-3036.

Sato, T., M. Arizono, R. Sone, and Y. Harada. 2008. Parasitemediated allochthonous input: Do hairworms enhance subsidized predation of stream salmonids on crickets? Canadian Journal of Zoology 86:231-235.

Thomas, F., A. Schmidt-Rhaesa, G. Martin, C. Manu, P. Durand, and F. Renaud. 2002. Do hairworms (Nematomorpha) manipulate the water seeking behaviour of their terrestrial hosts? Journal of Evolutionary Biology 153:356361.

Thompson, R. M., K. Mouristen, and R. Poulin. 2005. Importance of parasites and their life cycle characteristics in determining the structure of a large marine food web. Journal of Animal Ecology 74:77-85.

Wipfli, M. S. 1997. Terrestrial invertebrates as salmonid prey and nitrogen sources in streams: contrasting old-growth and young-growth riparian forests in southeastern Alaska, U.S.A. Canadian Journal of Fisheries and Aquatic Science 546:1259-1269.

Wootton, R. J. 1998. Ecology of teleost fishes. Second edition. Kluwer Academic, Dordrecht, The Netherlands.

\section{APPENDIX A}

Details of the calculation of energy values of prey organisms and the mass-based daily prey consumptions by Japanese trout and a table showing caloric- and mass-based values of prey ingested by trout (Ecological Archives E092-016-A1).

\section{APPENDIX B}

Abundance of hosts in the terrestrial habitat and predation rate of trout on hosts (Ecological Archives E092-016-A2).

\section{APPENDIX C}

Results from statistical analysis (Ecological Archives E092-016-A3). 